\title{
LINE-1 methylation in visceral adipose tissue of severely obese individuals is associated with metabolic syndrome status and related phenotypes
}

Valérie Turcot ${ }^{1,3}$, André Tchernof $^{2,4}$, Yves Deshaies ${ }^{4,5}$, Louis Pérusse ${ }^{1,6}$, Alexandre Bélisle ${ }^{7}$, Simon Marceau ${ }^{4,8}$, Simon Biron ${ }^{4,8}$, Odette Lescelleur ${ }^{4,8}$, Laurent Biertho ${ }^{4,8}$ and Marie-Claude Vohl $1^{1,3^{*}}$

\begin{abstract}
Background: Epigenetic mechanisms may be involved in the regulation of genes found to be differentially expressed in the visceral adipose tissue (VAT) of severely obese subjects with (MetS+) versus without (MetS-) metabolic syndrome (MetS). Long interspersed nuclear element 1 (LINE-1) elements DNA methylation levels (\% meth) in blood, a marker of global DNA methylation, have recently been associated with fasting glucose, blood lipids, heart diseases and stroke.
\end{abstract}

Aim: To test whether LINE-1\%meth levels in VAT are associated with MetS phenotypes and whether they can predict MetS risk in severely obese individuals.

Methods: DNA was extracted from VAT of 34 men (MetS-: $n=14$, MetS+: $n=20$ ) and 152 premenopausal women (MetS-: $n=84$; MetS+: $n=68$ ) undergoing biliopancreatic diversion for the treatment of obesity. LINE-1\%meth levels were assessed by pyrosequencing of sodium bisulfite-treated DNA.

Results: The mean LINE-1\%meth in VAT was of 75.8\% (SD =3.0\%). Multiple linear regression analyses revealed that LINE-1\%meth was negatively associated with fasting glucose levels $(\beta=-0.04 ; P=0.03)$, diastolic blood pressure $(\beta=$ $-0.65 ; P=0.03)$ and MetS status $(\beta=-0.04 ; P=0.004)$ after adjustments for the effects of age, sex, waist circumference (except for MetS status) and smoking. While dividing subjects into quartiles based on their LINE-1\%meth (Q1 to Q4: lower \%meth to higher \%meth levels), greater risk were observed in the first (Q1: odds ratio $(\mathrm{OR})=4.37, P=0.004)$ and the second (Q2: $\mathrm{OR}=4.76, P=0.002)$ quartiles compared to Q4 (1.00) when adjusting for age, sex and smoking.

Conclusions: These results suggest that lower global DNA methylation, assessed by LINE-1 repetitive elements methylation analysis, would be associated with a greater risk for MetS in the presence of obesity.

Keywords: Blood pressure, Epigenetics, Fasting glucose, Global DNA methylation, LINE-1, Metabolic syndrome, Severe obesity, Visceral adipose tissue

\footnotetext{
* Correspondence: marie-claude.vohl@fsaa.ulaval.ca

'Institute of Nutraceuticals and Functional Foods, 2440 Hochelaga Blvd,

Québec City GIV OA6, Canada

${ }^{3}$ Department of Food Sciences and Nutrition, Université Laval, 2425 de

l'Agriculture Av, Québec City GIV OA6, Canada

Full list of author information is available at the end of the article
} 


\section{Background}

Accumulation of fat preferentially in the abdominal cavity is frequently associated with clustering of metabolic and inflammatory alterations, often referred to as metabolic syndrome (MetS) $[1,2]$. However, there exists a large heterogeneity in the development of these metabolic complications among obese individuals $[3,4]$, which may partly be explained by impairment of adipose tissue function $[5,6]$. Previous studies observed differential gene expression patterns in visceral adipose tissue (VAT) of 'metabolically healthy' vs 'metabolically unhealthy' obese individuals [7-9]. It is thus possible that some of these differentially expressed genes may be functionally related to VAT dysfunction and MetS-related phenotypes. Although polymorphisms within several genes have previously been associated with both gene expression variability and MetS components [5], epigenetic mechanisms may also contribute to this variability.

Several epidemiological and animal studies demonstrated that a detrimental environment during fetal and postnatal periods, such as maternal obesity and gestational diabetes, is associated with increased risk of obesity and metabolic complications later in life [10,11]. These long-term complications would partly be explained by impaired organogenesis and cellular energy metabolism [12], as it may be the case regarding adipose tissue development and function [12-14]. Thus, impairments of normal development will ultimately change gene expression patterns in key metabolic pathways involved in obesity and MetS, which may potentially be mediated through epigenetic mechanisms $[15,16]$. DNA methylation is the most widely studied epigenetic phenomenon in humans. While association analyses between CpG methylation levels of candidate genes and complex diseases are increasing [17], an emerging literature uses CpG methylation of repetitive DNA sequences in disease association analyses [18]. This is the case for long interspersed nuclear element 1 (LINE-1) elements, which is a marker of the global DNA methylation of the genome [19]. LINE-1 elements are a family of transposon-derived sequence repeats dispersed in the genome [20]. These repetitive elements are normally heavily methylated and their hypomethylation is commonly associated with cancer development and progression [21,22].

Interestingly, recent epidemiological studies also identified some associations between LINE-1 methylation variability and ischemic heart disease and stroke [23], as well as with MetS phenotypes, such as plasma fasting glucose [24] and plasma lipid levels [24,25].

In view of the recent observations regarding blood LINE-1 methylation levels and MetS-related phenotypes, the aim of the present study was to test whether LINE-1 methylation levels in VAT are associated with MetS phenotypes and whether they can predict MetS risk in severely obese individuals.

\section{Methods}

\section{Patient selection}

The study subjects were severely obese Caucasian men (MetS-: $n=14$; MetS+: $n=20$ ) and premenopausal women (MetS-: $n=84$; MetS+: $n=68$ ) undergoing a biliopancreatic diversion with sleeve gastrectomy to treat obesity [26] at the Institut Universitaire de Cardiologie et de Pneumologie de Québec (Québec City, Canada) from June 2000 to June 2010, and for whom DNA samples from VAT were available. The study subjects were not taking any medications to treat MetS features and were not affected by type 2 diabetes mellitus [27]. Body weight, height, waist circumference, resting systolic and diastolic blood pressure were measured using standardized procedures [28]. The day of surgery, fasting blood samples were drawn into EDTA-containing tubes and centrifuged for plasma lipid and glucose concentration measurements [28]. VAT from the greater omentum was sampled during the surgery, as previously reported $[26,29]$. The diagnosis of MetS was based on the International Diabetes Federation (IDF) definition [30]. MetS + subjects had to be centrally obese (waist circumference $\geq 88 \mathrm{~cm}$ for women and $\geq 102 \mathrm{~cm}$ for men; USA cut-off values from the Adult Treatment Panel III [31]) with $\geq 2$ other MetS criteria among the following: fasting plasma glucose $\geq 5.6 \mathrm{mmol} / \mathrm{l}$, high-density lipoprotein (HDL)-cholesterol $<1.29 \mathrm{mmol} / \mathrm{l}$ for women and $<1.03 \mathrm{mmol} / \mathrm{l}$ for men, triglycerides $\geq 1.7 \mathrm{mmol} / \mathrm{l}$, systolic blood pressure (SBP) $\geq 130 \mathrm{mmHg}$ or diastolic blood pressure (DBP) $\geq 85 \mathrm{mmHg}$. All subjects provided a written informed consent to participate in this study, which received the approval of Université Laval Ethics Committee.

\section{Analysis of LINE-1 CpG methylation in VAT}

DNA was extracted from VAT using the DNeasy Blood \& Tissue kit (Qiagen, Mississauga, Ontario, Canada), as recommended by the manufacturer. DNA extracts were stored at $-80^{\circ} \mathrm{C}$ until quantitative methylation analysis using the pyrosequencing technology from Qiagen [32], which was performed by the McGill University and Genome Québec Innovation Center Genotyping Platform team (Montréal, Canada). DNA $(1 \mu \mathrm{g})$ was treated with sodium bisulfite followed by a purification step using the EZ-96 DNA Methylation-Gold kit (Zymo Research, Orange, CA, USA). The polymerase chain reaction (PCR) was performed in a $25 \mu \mathrm{l}$ total volume. The final concentrations were: $0.05 \mathrm{U} / \mu \mathrm{l}$ for Qiagen HotStarTaq DNA Polymerase with $1.25 \times$ PCR buffer, plus $1.0 \mathrm{mM}$ of magnesium chloride, $0.2 \mu \mathrm{M}$ for each primer and $0.50 \mathrm{mM}$ for dNTP mix (Roche NucleoMix). PCR started with an initial denaturation of 15 minutes at $95^{\circ} \mathrm{C}$ followed by 45 cycles of $20 \mathrm{~s}$ at $95^{\circ} \mathrm{C}, 30 \mathrm{~s}$ at $56^{\circ} \mathrm{C}$ and $60 \mathrm{~s}$ at $72^{\circ} \mathrm{C}$; the reaction finished with 5 minutes at $72^{\circ} \mathrm{C}$. PCR products were purified and sequenced by pyrosequencing as previously described [33] using $0.3 \mu \mathrm{M}$ sequencing primer. Primer 
sequences were previously published [34,35], and are the following: forward, 5'-TTT TGA GTT AGG TGT GGG ATA TA-3'; reverse, 5' -Biotin-AAA ATC AAA AAA TTC CCT TTC-3'; and sequencing, 5'-AGT TAG GTG TGG GAT ATA GT-3'. The targeted region comprised three CpGs located in the $5^{\prime}$ region of LINE-1 elements [19] and had the following bisulfite-treated DNA sequence: 5 '-TTC/ TGTGGTGC/TGTC/TG-3', where C/T corresponded to methylated $(\mathrm{C})$ and unmethylated $(\mathrm{T})$ cytosine at each $\mathrm{CpG}$ site. Since the \%meth levels of the three CpG sites were highly correlated between each other $(r=0.57-0.83, P$ $<0.0001$ ), the mean \%meth of combined LINE-1 CpG sites was calculated for each subject and used in the association analyses.

\section{Statistical analysis}

Non-normally distributed phenotypes were $\log _{10}$ or negative inverse transformed. The general linear model (GLM) and the type III sum of squares (all subjects: sex included in the model; sex-specific: unadjusted) were used to compare the mean phenotype levels between subjects without (MetS-) and with (MetS+) MetS. Multiple linear regression analyses were performed to predict each MetS-related phenotype and MetS per se while including $L I N E-1 \%$ meth as an independent variable along with MetS-related potential confounding factors (see the Results section for more details about adjustments). After dividing the subjects into quartiles based on their LINE-1\%meth and dichotomized by MetS- and $\mathrm{MetS}+$ groups, a logistic regression analysis was performed to compute odds ratios (ORs) and Wald's confidence limits to evaluate whether $L I N E-1 \%$ meth quartiles can predict MetS risk. Finally, a multiple linear regression analysis was used to predict LINE-1\%meth levels where age, sex and smoking were included in the model as independent variables. The statistically significant $P$ value was set at 0.05 . Statistical analyses were performed using SAS software V.9.2 (SAS Institute, Cary, NC, USA).

\section{Results}

\section{Characteristics of the study subjects in MetS- and} MetS + groups

The characteristics of the subjects are presented in Table 1. No difference was observed in the mean age and smoking frequencies between MetS groups. Study subjects were severely obese with a mean body mass index of about $52 \mathrm{~kg} / \mathrm{m}^{2}$ and a mean age of about 35 years. Women in the MetS + group had higher mean body mass index and waist circumference values compared to MetS- women. As expected, all the mean MetS-related phenotypes differed significantly between MetS groups.

\section{Relationship between LINE-1\%meth levels, MetS and its related phenotypes}

The mean LINE-1\%meth in VAT of 186 severely obese subjects was of $75.8 \%(\mathrm{SD}=3.0 \%$ ) with values ranging from 67.3 to $85.4 \%$. Regression coefficients obtained specifically for $L I N E-1 \%$ meth in predictive models for each MetSrelated phenotype and MetS per se are shown in Table 2. Negative associations were seen between LINE-1\%meth levels and fasting glucose levels $(\beta$ (95\% confidence interval $)=-0.04(-0.08$ to -0.01$) ; P=0.03)$ and DBP $(-0.65(-1.26$ to -0.05$) ; P=0.03)$ when age, sex, waist circumference and smoking were included in the model. LINE-1\%meth levels were also significantly predicting MetS per se (-0.04 (-0.06 to -0.01$) ; P=0.004)$ when adjusted for age, sex and smoking. Of note, $\mathrm{CpG}$ site specific complementary analyses revealed that methylation levels of the first CpG site investigated in this assay were more closely related to the previous MetS phenotypes (fasting glucose: $\beta=-0.04, P=0.007$; DBP: $\beta=-0.52, P=0.04$; and MetS per se: $\beta=-0.04$, $P=0.0002)$, and also with the SBP $(\beta=-0.88, P=0.01)$, as compared to methylation levels of the second and the third CpG sites ( $P>0.05$ for the whole model; data not shown).

\section{Prediction of MetS risk using quartiles of LINE-1\%meth in VAT}

The study subjects were divided into quartiles (Q) based on their LINE-1\%meth levels (Q1: 67.3\% to 73.8\%; Q2: 73.8\% to $75.0 \%$; Q3: $75.0 \%$ to $77.3 \%$; Q4: $77.3 \%$ to $85.4 \%$ ) and dichotomized into MetS- and MetS + groups. ORs were computed to evaluate whether some LINE-1\%meth quartiles may be associated with greater risk of MetS, while taking the higher \%meth quartile as the reference group. Greater risks were observed in the first (OR (95\% confidence limits (CL); Q1: OR=4.37 (1.59 to 12.01$), P=0.004$ ) and the second (Q2: $\mathrm{OR}=4.76$ (1.76 to 12.90$), P=0.002$ ) quartiles compared to Q4 (1.00), which was not the case for the third quartile $(\mathrm{Q} 3: \mathrm{OR}=1.82(0.70$ to 4.71$), P=0.22)$ when adjusting for age, sex and smoking (Table 3 ). While using a cut-off point of $75.0 \%$ for LINE-1\%meth levels, the sensitivity and specificity of correctly categorizing subjects as having or not having MetS were $60.2 \%$ and $59.2 \%$, respectively. Although the \%meth cut-off point that would confer greater risk for MetS seems slightly different in additional site specific analyses, practically the same observation could be drawn, that is, quartiles with lower \%meth levels for each $\mathrm{CpG}$ site were associated with greater MetS risk $\left(\mathrm{Q} 1\right.$ for $\mathrm{CpG}_{1,2}$ : $\mathrm{OR}=2.82$ to $8.34, P<0.04$; $\mathrm{Q} 2$ for $\mathrm{CpG}_{1,2}: \mathrm{OR}=2.80$ to $8.16, P<0.04 ; \mathrm{Q} 3$ for $\mathrm{CpG}_{1}: \mathrm{OR}=$ $2.71, P=0.047)$, as compared to the highest \%meth quartile (Q4) (data not shown).

\section{Predictors of LINE-1\%meth levels in VAT}

The contribution of potential confounding factors in LINE-1\%meth variation was tested using a multiple linear 
Table 1 Subject characteristics according to metabolic syndrome (MetS) status

\begin{tabular}{|c|c|c|c|c|c|c|}
\hline \multirow[b]{2}{*}{ Phenotypes $^{a}$} & \multicolumn{2}{|l|}{ All subjects } & \multicolumn{2}{|l|}{ Men } & \multicolumn{2}{|c|}{ Premenopausal women } \\
\hline & MetS- & MetS+ & MetS- & MetS+ & MetS- & MetS+ \\
\hline No. of subjects $(n)$ & 98 & 88 & 14 & 20 & 84 & 68 \\
\hline Smokers ( $n)$ & $21(21.4 \%)$ & $22(25.6 \%)$ & $2(14.3 \%)$ & $4(21.1 \%)$ & $19(22.6 \%)$ & $18(26.9 \%)$ \\
\hline Age (years) & $34.9 \pm 8.1$ & $35.3 \pm 7.3$ & $32.2 \pm 8.9$ & $36.8 \pm 9.2$ & $35.4 \pm 7.9$ & $34.9 \pm 6.7$ \\
\hline Body Mass Index $\left(\mathrm{kg} / \mathrm{m}^{2}\right)^{\mathrm{b}}$ & $49.8 \pm 8.4$ & $53.8 \pm 10.8^{*}$ & $54.5 \pm 8.8$ & $56.8 \pm 13.1$ & $49.0 \pm 8.1$ & $52.9 \pm 9.9^{* *}$ \\
\hline Waist circumference $(\mathrm{cm})$ & $130.1 \pm 17.0$ & $139.4 \pm 19.6^{* *}$ & $151.6 \pm 15.6$ & $160.7 \pm 20.7$ & $126.8 \pm 14.7$ & $132.9 \pm 14.0^{*}$ \\
\hline Fasting glucose $(\mathrm{mmol} / \mathrm{ll})^{\mathrm{b}}$ & $4.87 \pm 0.39$ & $5.68 \pm 0.87^{* * *}$ & $5.06 \pm 0.33$ & $6.16 \pm 0.75^{* * *}$ & $4.84 \pm 0.39$ & $5.53 \pm 0.86^{* * *}$ \\
\hline Triglycerides $(\mathrm{mmol} / \mathrm{l})^{b}$ & $1.13 \pm 0.37$ & $2.20 \pm 1.14^{* * *}$ & $1.08 \pm 0.31$ & $2.42 \pm 1.41^{* * *}$ & $1.13 \pm 0.38$ & $2.13 \pm 1.06^{* * *}$ \\
\hline High-density lipoprotein-cholesterol (mmol/l) & $1.47 \pm 0.26$ & $1.09 \pm 0.20^{* * *}$ & $1.27 \pm 0.17$ & $0.94 \pm 0.15^{* * *}$ & $1.51 \pm 0.38$ & $1.13 \pm 0.20^{* * *}$ \\
\hline Systolic blood pressure (mmHg) & $130.2 \pm 13.4$ & $144.6 \pm 17.2^{* * *}$ & $132.1 \pm 12.8$ & $150.2 \pm 19.4^{* *}$ & $129.9 \pm 13.5$ & $143.0 \pm 16.4^{* * *}$ \\
\hline Diastolic blood pressure $(\mathrm{mmHg})^{\text {b }}$ & $79.9 \pm 9.3$ & $90.4 \pm 11.9^{* * *}$ & $78.8 \pm 7.8$ & $89.7 \pm 13.2^{*}$ & $80.0 \pm 8.7$ & $90.6 \pm 11.6^{* * *}$ \\
\hline
\end{tabular}

${ }^{\mathrm{a}}$ Data are shown as mean \pm SD or $n$.

${ }^{b}$ Non-normally distributed phenotypes were transformed for the general linear model analysis: body mass index (negative inverse: $\left.-1 /(\mathrm{X})\right)$, fasting glucose $(-1 /(\mathrm{X}))$, triglycerides $(-1 /(1+\mathrm{X}))$ and diastolic blood pressure $(-1 /(\mathrm{X}))$.

${ }^{*} P<0.05,{ }^{* *} P<0.01,{ }^{* * *} P<0.0001$; for differences in mean phenotype levels between MetS- and MetS + groups.

regression model including age, sex and smoking. The variance was partly accounted for by sex ( $\beta$ (95\% confidence interval $)=-3.21 \quad(-4.27$ to -2.15$) ; \quad P<0.0001$; lower in women). Other factors were not significant (age: $0.04(-0.02$ to 0.09$), P=0.17$; smoking: 0.33 (-0.64 to 1.29$), P=0.50$ ).

\section{Discussion}

This study revealed that LINE-1\%meth levels in VAT were associated negatively with fasting plasma glucose, blood pressure and MetS per se using the IDF definition [30]. Subjects situated in the quartiles with lower LINE-1\%meth levels had significantly greater risk to be affected by MetS when adjusted for age, sex and smoking. Sex was a significant predictor of LINE-1\%meth levels in VAT of the study subjects, which was not the case for age and smoking. To the best of our knowledge, this is the first study analyzing LINE-1\%meth levels in adipose tissue. Most of the published studies used peripheral blood cells [18,23,25,36-38], tumorous vs non-tumorous tissues [39,40], and placental tissues [41] for LINE-1 methylation analysis. LINE-1\% meth levels observed in VAT of the study subjects were comparable to levels reported in previous epidemiological studies using white blood cells (WBC) and the same methylation quantification method [18,23]. It thus suggests that LINE-1\%meth levels between VAT and WBC are comparable, even though the correlation between both compartments was not tested in the present study. Although further studies would be needed to investigate whether LINE-1\%meth levels in WBC are associated with MetS risk, as a more convenient biological sample for clinical and epidemiological purposes, this study underlines the presence of DNA methylation heterogeneity in the VAT of severe obese individuals. This finding supports the hypothesis of potential epigenetic changes in VAT, which may contribute to the development of metabolic perturbations in the presence of abdominal obesity. Since

Table 2 Multiple linear regression analysis predicting metabolic syndrome (MetS)-related phenotypes while including LINE-1 methylation level (LINE-1\%meth) in the predictive model

\begin{tabular}{|c|c|c|c|}
\hline \multirow[t]{2}{*}{ Dependent variables } & \multicolumn{3}{|c|}{ LINE-1\%meth } \\
\hline & $\bar{N}$ & $\beta(95 \% \mathrm{Cl})^{\text {model }}$ & $P$ value \\
\hline Waist circumference $(\mathrm{cm})$ & 180 & $-0.51(-1.33 \text { to } 0.32)^{\mathrm{A}}$ & 0.23 \\
\hline Fasting glucose (mmol/l) & 179 & $-0.04(-0.08 \text { to }-0.01)^{B}$ & 0.03 \\
\hline Triglycerides (mmol/l) & 179 & $0.01(-0.04 \text { to } 0.06)^{B}$ & 0.64 \\
\hline High-density lipoprotein-cholesterol (mmol/l) & 179 & $0.01(-0.003 \text { to } 0.03)^{B}$ & 0.13 \\
\hline Systolic blood pressure $(\mathrm{mmHg})$ & 180 & $-0.71(-1.55 \text { to } 0.13)^{\mathrm{B}}$ & 0.10 \\
\hline Diastolic blood pressure $(\mathrm{mmHg})$ & 180 & $-0.65(-1.26 \text { to }-0.05)^{B}$ & 0.03 \\
\hline MetS $(n)$ & 184 & $-0.04(-0.06 \text { to }-0.01)^{\mathrm{A}}$ & 0.004 \\
\hline
\end{tabular}

Only coefficients $(\beta), 95 \%$ confidence intervals $(95 \% \mathrm{Cl})$ and $P$ values accounted for by the independent variable LINE-1\%meth levels are shown in the table. The coefficient $\beta$ corresponds to the change in the dependent variable per unit change in LINE-1\%meth, given that all the other variables in the model remain constant.

Model A: LINE-1\%meth, age, sex and smoking.

Model B: LINE-1\%meth, age, sex, smoking and waist circumference. 
Table 3 Logistic regression analysis evaluating the association between LINE-1 methylation level (LINE-1\%meth) quartiles and metabolic syndrome (MetS) risk

\begin{tabular}{|c|c|c|c|c|}
\hline LINE-1\%meth quartiles & MetS-, $n=98$ & MetS+, $n=86$ & Wald's $X^{2}=12.3, P=0.007^{\mathrm{a}}, \mathrm{OR}(95 \% \mathrm{CL})$ & $P$ value \\
\hline Q1: $67.3 \%$ to $73.8 \%$ & $21(0.22)$ & $25(0.29)$ & 4.37 (1.59 to 12.02$)$ & 0.004 \\
\hline Q2: $73.8 \%$ to $75.0 \%$ & $19(0.19)$ & $27(0.31)$ & $4.76(1.76$ to 12.90$)$ & 0.002 \\
\hline Q3: $75.0 \%$ to $77.3 \%$ & $28(0.29)$ & $18(0.21)$ & $1.82(0.70$ to 4.71$)$ & 0.22 \\
\hline Q4: $77.3 \%$ to $85.0 \%$ & $30(0.31)$ & $16(0.18)$ & 1.00 & - \\
\hline
\end{tabular}

Odds ratios and $P$ values computed by the logistic regression analysis were obtained while including potential confounding factors in the model, namely age, sex and smoking. The fourth $L I N E-1 \%$ meth quartile (Q4) was set as the reference group.

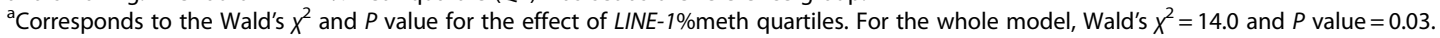
$C L=$ Wald's confidence limits.

differential gene expression patterns were previously observed in VAT of obese with versus without MetS [7], gene-specific DNA methylation analysis in VAT are warranted to better understand the contribution of epigenetics in VAT function and, consequently, in obesity-related metabolic disorders.

The study results showed higher plasma glucose and DBP levels, along with greater risk for MetS, in presence of lower LINE-1\%meth levels in VAT. However, this relationship is in the opposite direction of what Pearce et al. reported [24]. In their samples of 228 Caucasian individuals aged 49 to 51 years from the Newcastle Thousand Families Study (Newcastle upon Tyne, UK), they found a positive association between peripheral blood LINE-1\% meth and fasting glucose levels. They also observed positive and negative associations, respectively, with plasma triglyceride and HDL-cholesterol levels after adjustment for sex [24]. In contrast, Kim et al. reported no significant association between blood LINE-1\%meth levels and fasting glucose, triglyceride, HDL-cholesterol, SBP and DBP in healthy male and female Koreans [42]. Since their study sample was relatively small $(n=86)$ and that no adjustments for sex were performed, it is difficult to clearly delineate the direction of the relationship between LINE-1\%meth and MetS-related phenotypes. However, since most studies reported that lower LINE$1 \%$ meth levels in peripheral blood cells were associated with lower HDL-cholesterol levels [25] and with higher risk of incident ischemic heart disease and stroke [23], it is tempting to suggest that lower LINE-1\%meth levels may be associated with MetS and its related phenotypes.

Regarding potential predictors of $L I N E-1 \%$ meth, lower methylation levels were observed in VAT of women as compared to men in this study, which was also reported in several studies using WBC for LINE-1\%meth quantification $[19,38,43,44]$. The reason for this sex difference still remains to be clarified, but it does not appear to be related to male/female hormone differences [44,45]. While there is growing evidence that WBC global DNA methylation reduces with aging, several studies did not observe an association between LINE-1\%meth levels with either age [38,44], or active cigarette smoking in adults [38]. Consistent with these previous studies, age and smoking were not significant predictors of LINE-1\% meth levels in VAT of the present study subjects.

As reported in a previous study, many genes were differentially expressed in VAT of MetS- versus MetS + severely obese men [7] and epigenetic mechanisms have been postulated as potentially mediating differential expressions [33]. There is recent evidence supporting a correlation between LINE-1 and gene-specific \%meth levels, which would depend upon the genomic region and type of tissue analyzed [46]. However, the nature of this relationship still remains underexplored. The relevance of LINE-1 methylation quantification as a marker of global DNA methylation is supported by the fact that LINE-1 is the most prevalent repetitive sequence in the human genome (approximately $17 \%$ of the genome) [20] and that about one-third of DNA methylation in the genome occurs in these elements [35]. Some reports have also shown that $L I N E-1 \%$ meth levels significantly correlated with other methods assessing global DNA methylation, such as genomic 5-methyl cytosine content [47] and luminometric methylation assay (LUMA) [46]. Bisulfite sequencing of repetitive elements, as performed here for LINE-1 elements, is a quicker and easier method to assess global DNA methylation as compared to genomic 5-methyl cytosine quantification [35]. Thus, all the above observations would support the utility of assessing LINE-1\%meth as a marker of global DNA methylation in VAT of our study subjects, and suggest that the variability observed in $L I N E-1 \%$ meth levels may be suggestive of concomitant variability in gene-specific \%meth levels potentially associated with differential gene expression and MetS phenotypes. It should be mentioned that methylation quantification of other repetitive elements, such as Alu repeats, is sometimes performed to assess global DNA methylation [18], which was not measured in this study. Correlations between LINE-1 and Alu methylation levels were observed in some but not all studies $[18,48]$ and may depend on the type of tissues examined and the responses to cellular stressors and environmental exposures [18]. LINE-1 and Alu repeats represent distinct measures of dispersed DNA 
methylation [19] and it is unknown whether the same associations observed in this study would be seen with Alu methylation levels. LINE-1 methylation assessment was chosen in this study over Alu because of previous associations between LINE-1 methylation levels and MetS phenotypes $[24,25]$, as well as with ischemic heart disease and stroke [23]. Another reason for investigating LINE-1 elements is its function. There are approximately 3,000 to 5,000 full length (approximately $6 \mathrm{~kb}$ ) LINE-1 sequences throughout the genome, which comprise the $5^{\prime}$ region targeted in the LINE- $1 \%$ meth analysis, in which approximately 60 to 100 elements are still capable of retrotransposition [49]. It has been postulated in cancer that demethylation of LINE-1 elements may increase their retrotransposable activity, induce genomic instability, and deregulate transcriptional activity of specific genes [50]. Whether such a portrait would also be seen in other common complex diseases is unknown.

Some study limitations need to be outlined, such as the possibility of reverse causality [17]. It is indeed possible that the development of obesity-related metabolic complications may have induced changes in LINE-1\%meth rather than the reverse. Furthermore, DNA methylation of LINE-1 elements has been associated with several environmental exposures, such as air pollution, metal exposures, persistent organic pollutants, as well as alcohol and dietary folate consumption (reviewed in [38]). Whether these confounding factors have influenced LINE-1\%meth variability in this study and consequently changed the relationship seen with MetS is unknown. It may however need some concerns since several persistent organic pollutants may accumulate in adipose tissue, which have been attributed with obesity development, type 2 diabetes and related metabolic impairments in human and animal models $[51,52]$. Also, VAT is a heterogeneous tissue composed of different cell types, including infiltrated lymphocytes [53], which are increased in presence of obesity and associated with insulin resistance [54]. It has been shown that the percentage of lymphocytes in blood cell counts was negatively associated with blood LINE-1\%meth levels [18]. Whether our MetS + subjects have greater lymphocyte infiltration in their VAT, which may influence LINE-1\%meth values obtained in this study, is a possibility which warrants further investigation. Finally, Zhang et al. have previously reported that some variability in LINE-1 methylation levels exist in peripheral leukocytes among cancer-free individuals of different ethnicities [43]. These authors proposed that genetic polymorphisms in the folate metabolism, which provides methyl groups for DNA methylation [55], or other unknown genetic and environmental factors, may contribute to ethnic differences in global DNA methylation [43]. It thus suggests that associations observed among Caucasians in the present study may not necessarily be generalized to all ethnic groups and may potentially be influenced by genetic polymorphisms.

\section{Conclusions}

In summary, this study revealed that lower LINE-1\%meth levels in VAT of non-diabetic severely obese subjects was associated with higher plasma glucose and DBP levels, and with a greater risk to be affected by MetS. This investigation also point out to the necessity to pursue gene-specific methylation analysis among differentially expressed genes in the VAT of severely obese subjects MetS- and MetS + [7] to better understand the involvement of epigenetic regulation in the development of obesity-related metabolic complications.

\section{Competing interests}

The authors declare that they have no competing interests.

\section{Authors' contributions}

$V T$ initiated the study, performed the statistical analyses, interpreted the data and drafted the manuscript. AT, YD, and LP participated to the elaboration of the study design. $A B$ was in charge of the methylation analysis. SM, SB, OL, LB sampled blood and adipose tissue from the study subjects. MCV conceived and designed the study. All authors read and approved the final manuscript.

\section{Acknowledgments}

This study was supported by a grant from the Canadian Institutes of Health Research (CIHR: MOP-209380). The severely obese cohort was supported, over the years, by the Université Laval Research Chair in Obesity. We express our gratitude to surgeons Picard Marceau, Frédéric-Simon Hould and Stéfane Lebel of the Institut Universitaire de Cardiologie et de Pneumologie de Québec who have sampled adipose tissues for this project, as well as Paule Marceau for patients' database management. Many thanks are also expressed to Fanny Therrien and Caroline Nadeau for their help in adipose tissue banking management, as well as to Alain Houde and Catherine Raymond for DNA banking management and laboratory analyses support. VT received studentship awards from the Canadian Institutes of Health Research and the Fonds de la Recherche en Santé du Québec. AT is a research scholar from the Fonds de la Recherche en Santé du Québec and holder of a

Research Chair in Bariatric and Metabolic Surgery. MCV holds a Tier 1 Canada Research Chair in Genomics Applied to Nutrition and Health.

\section{Author details}

${ }^{1}$ Institute of Nutraceuticals and Functional Foods, 2440 Hochelaga Blvd, Québec City G1V 0A6, Canada. ${ }^{2}$ Molecular Endocrinology and Genomics, CHUL Research Center, 2705 Laurier Blvd, Québec City G1V 4G2, Canada. ${ }^{3}$ Department of Food Sciences and Nutrition, Université Laval, 2425 de I'Agriculture Av, Québec City G1V 0A6, Canada. ${ }^{4}$ Centre de Recherche de I'Institut Universitaire de Cardiologie et de Pneumologie de Québec, 2725 Sainte-Foy Rd, Québec City G1V 4G5, Canada. ${ }^{5}$ Department of Medicine, Université Laval, 1050 de la Médecine Av, Québec City G1V 0A6, Canada. ${ }^{6}$ Department of Kinesiology, Université Laval, 2300 de la Terrasse Street, Québec City G1V 0A6, Canada. ${ }^{7}$ Genotyping Platform Team, McGill University and Génome Québec Innovation Center, 740 Docteur-Penfield Av, Montréal H3A 1A4, Canada. ${ }^{8}$ Department of Surgery, Université Laval, 1050 de la Médecine Av, Québec City G1V 0A6, Canada.

Received: 14 March 2012 Accepted: 21 May 2012

Published: 2 July 2012

\section{References}

1. Alberti KG, Eckel RH, Grundy SM, Zimmet PZ, Cleeman Jl, Donato KA, Fruchart JC, James WP, Loria CM, Smith SC Jr: Harmonizing the metabolic syndrome: a joint interim statement of the International Diabetes Federation Task Force on Epidemiology and Prevention; National Heart, Lung, and Blood Institute; American Heart Association; World Heart Federation; International Atherosclerosis Society; and International Association for the Study of Obesity. Circulation 2009, 120:1640-1645.

2. Mathieu P, Lemieux I, Despres JP: Obesity, inflammation, and cardiovascular risk. Clin Pharmacol Ther 2010, 87:407-416. 
3. Pajunen P, Kotronen A, Korpi-Hyovalti E, Keinanen-Kiukaanniemi S, Oksa H, Niskanen L, Saaristo T, Saltevo JT, Sundvall J, Vanhala M, Uusitupa M, Peltonen M: Metabolically healthy and unhealthy obesity phenotypes in the general population: the FIN-D2D Survey. BMC Publ Health 2011, 11:754.

4. Primeau V, Coderre L, Karelis AD, Brochu M, Lavoie ME, Messier V, Sladek R, Rabasa-Lhoret R: Characterizing the profile of obese patients who are metabolically healthy. Int J Obes (Lond) 2011, 35:971-981.

5. Bluher M: Adipose tissue dysfunction in obesity. Exp Clin Endocrinol Diabetes 2009, 117:241-250.

6. Bluher M: The distinction of metabolically 'healthy' from 'unhealthy' obese individuals. Curr Opin Lipidol 2010, 21:38-43.

7. Bouchard L, Tchernof A, Deshaies Y, Marceau S, Lescelleur O, Biron S, Vohl MC ZFP36: a promising candidate gene for obesity-related metabolic complications identified by converging genomics. Obes Surg 2007, 17:372-382.

8. Hardy OT, Perugini RA, Nicoloro SM, Gallagher-Dorval K, Puri V, Straubhaar J, Czech MP: Body mass index-independent inflammation in omental adipose tissue associated with insulin resistance in morbid obesity. Surg Obes Relat Dis 2011, 7:60-67.

9. Klimcakova E, Roussel B, Kovacova Z, Kovacikova M, Siklova-Vitkova M, Combes M, Hejnova J, Decaunes P, Maoret JJ, Vedral T, Viguerie N, Bourlier $\checkmark$, Bouloumie A, Stich $V$, Langin D: Macrophage gene expression is related to obesity and the metabolic syndrome in human subcutaneous fat as well as in visceral fat. Diabetologia 2011, 54:876-887.

10. Delisle $\mathrm{H}$ : Programming of chronic disease by impaired fetal nutrition: evidence and implications for policy and intervention strategies. Report of the Department of Nutrition for Health and Development, Department of Noncommunicable Disease Prevention and Health Promotion. Geneva: World Health Organization; 2002

11. McMillen IC, Robinson JS: Developmental origins of the metabolic syndrome: prediction, plasticity, and programming. Physiol Rev 2005, 85:571-633.

12. Symonds ME, Sebert SP, Hyatt MA, Budge H: Nutritional programming of the metabolic syndrome. Nat Rev Endocrinol 2009, 5:604-610.

13. Fall $\mathrm{CH}$ : Evidence for the intra-uterine programming of adiposity in later life. Ann Hum Biol 2011, 38:410-428.

14. Muhlhausler B, Smith SR: Early-life origins of metabolic dysfunction: role of the adipocyte. Trends Endocrinol Metab 2009, 20:51-57.

15. Bruce KD, Cagampang FR: Epigenetic priming of the metabolic syndrome. Toxicol Mech Methods 2011, 21:353-361.

16. Campion J, Milagro Fl, Martinez JA: Individuality and epigenetics in obesity. Obes Rev 2009, 10:383-392.

17. Relton CL, Davey SG: Epigenetic epidemiology of common complex disease: prospects for prediction, prevention, and treatment. PLoS Med 2010, 7:e1000356.

18. Zhu ZZ, Hou L, Bollati V, Tarantini L, Marinelli B, Cantone L, Yang AS, Vokonas P, Lissowska J, Fustinoni S, Pesatori AC, Bonzini M, Apostoli P, Costa G, Bertazzi PA, Chow WH, Schwartz J, Baccarelli A: Predictors of global methylation levels in blood DNA of healthy subjects: a combined analysis. Int J Epidemiol 2010, 41:126-139.

19. Nelson HH, Marsit CJ, Kelsey KT: Global methylation in exposure biology and translational medical science. Environ Health Perspect 2011, 119:1528-1533.

20. Lander ES, Linton LM, Birren B, Nusbaum C, Zody MC, Baldwin J, Devon K, Dewar K, Doyle M, FitzHugh W, Funke R, Gage D, Harris K, Heaford A, Howland J, Kann L, Lehoczky J, LeVine R, McEwan P, McKernan K, Meldrim J, Mesirov JP, Miranda C, Morris W, Naylor J, Raymond C, Rosetti M, Santos R, Sheridan A, Sougnez C, et al: Initial sequencing and analysis of the human genome. Nature 2001, 409:860-921

21. Sunami E, de MM, Vu A, Turner RR, Hoon DS: LINE-1 hypomethylation during primary colon cancer progression. PLoS One 2011, 6:e18884

22. Zhu ZZ, Sparrow D, Hou L, Tarantini L, Bollati V, Litonjua AA, Zanobetti A, Vokonas P, Wright RO, Baccarelli A, Schwartz J: Repetitive element hypomethylation in blood leukocyte DNA and cancer incidence, prevalence, and mortality in elderly individuals: the Normative Aging Study. Cancer Causes Control 2011, 22:437-447.

23. Baccarelli A, Wright R, Bollati V, Litonjua A, Zanobetti A, Tarantini L, Sparrow $D$, Vokonas $P$, Schwartz J: Ischemic heart disease and stroke in relation to blood DNA methylation. Epidemiology 2010, 21:819-828.

24. Pearce MS, McConnell JC, Potter C, Barrett LM, Parker L, Mathers JC, Relton CL: Global LINE-1 DNA methylation is associated with blood glycaemic and lipid profiles. Int J Epidemiol 2012, 41:210-217.

25. Cash HL, McGarvey ST, Houseman EA, Marsit CJ, Hawley NL, LambertMesserlian GM, Viali S, Tuitele J, Kelsey KT: Cardiovascular disease risk factors and DNA methylation at the LINE-1 repeat region in peripheral blood from Samoan Islanders. Epigenetics 2011, 6:1257-1264.

26. Marceau P, Hould FS, Simard S, Lebel S, Bourque RA, Potvin M, Biron S: Biliopancreatic diversion with duodenal switch. World J Surg 1998, 22:947-954

27. The Expert Committee on the Diagnosis and Classification of Diabetes Mellitus: Report of the expert committee on the diagnosis and classification of diabetes mellitus. Diabetes Care 2003, 26(Suppl 1):S5-S20

28. Vohl MC, Houde A, Lebel S, Hould FS, Marceau P: Effects of the peroxisome proliferator-activated receptor-gamma co-activator-1 Gly482Ser variant on features of the metabolic syndrome. Mol Genet Metab 2005, 86:300-306.

29. Vohl MC, Sladek R, Robitaille J, Gurd S, Marceau P, Richard D, Hudson TJ, Tchernof A: A survey of genes differentially expressed in subcutaneous and visceral adipose tissue in men. Obes Res 2004, 12:1217-1222.

30. Alberti KG, Zimmet P, Shaw J: Metabolic syndrome--a new world-wide definition. A Consensus Statement from the International Diabetes Federation. Diabet Med 2006, 23:469-480.

31. Expert Panel on Detection EaToHBCiA: Executive Summary of The Third Report of The National Cholesterol Education Program (NCEP) Expert Panel on Detection, Evaluation, And Treatment of High Blood Cholesterol In Adults (Adult Treatment Panel III). JAMA 2001, 285:2486-2497.

32. England R, Pettersson M: Pyro Q-CpG: quantitative analysis of methylation in multiple CpG sites by pyrosequencing. Nature Methods 2005, 2. doi:10.1038.

33. Turcot V, Bouchard L, Faucher G, Tchernof A, Deshaies Y, Perusse L, Belisle A, Marceau S, Biron S, Lescelleur O, Biertho L, Vohl MC: DPP4 gene DNA methylation in the omentum is associated with its gene expression and plasma lipid profile in severe obesity. Obesity (Silver Spring) 2011, 19:388-395.

34. Kile ML, Baccarelli A, Tarantini L, Hoffman E, Wright RO, Christiani DC Correlation of global and gene-specific DNA methylation in maternalinfant pairs. PLoS One 2010, 5:e13730

35. Yang AS, Estecio MR, Doshi K, Kondo Y, Tajara EH, Issa JP: A simple method for estimating global DNA methylation using bisulfite PCR of repetitive DNA elements. Nucleic Acids Res 2004, 32:e38

36. Baccarelli A, Tarantini L, Wright RO, Bollati V, Litonjua AA, Zanobetti A, Sparrow D, Vokonas P, Schwartz J: Repetitive element DNA methylation and circulating endothelial and inflammation markers in the VA normative aging study. Epigenetics 2010, 5:222-228.

37. Choi JY, James SR, Link PA, McCann SE, Hong CC, Davis W, Nesline MK Ambrosone CB, Karpf AR: Association between global DNA hypomethylation in leukocytes and risk of breast cancer. Carcinogenesis 2009, 30:1889-1897.

38. Terry MB, Delgado-Cruzata L, Vin-Raviv N, Wu HC, Santella RM: DNA methylation in white blood cells: association with risk factors in epidemiologic studies. Epigenetics 2011, 6:828-837.

39. Irahara N, Nosho K, Baba Y, Shima K, Lindeman NI, Hazra A, Schernhamme ES, Hunter DJ, Fuchs CS, Ogino S: Precision of pyrosequencing assay to measure LINE-1 methylation in colon cancer, normal colonic mucosa, and peripheral blood cells. J Mol Diagn 2010, 12:177-183.

40. Pavicic $W$, Joensuu El, Nieminen T, Peltomaki P: LINE-1 hypomethylation in familial and sporadic cancer. J Mol Med (Berl) 2012. doi:10.1007/s00109011-0854-z.

41. Wilhelm-Benartzi CS, Houseman EA, Maccani MA, Poage GM, Koestler DC, Langevin SM, Gagne LA, Banister C, Padbury JF, Marsit CJ: In utero exposures, infant growth, and DNA methylation of repetitive element and developmentally related genes in human placenta. Environ Health Perspect 2012, 120:296-302.

42. Kim KY, Kim DS, Lee SK, Lee IK, Kang JH, Chang YS, Jacobs DR, Steffes M, Lee $\mathrm{DH}$ : Association of low-dose exposure to persistent organic pollutants with global DNA hypomethylation in healthy Koreans. Environ Health Perspect 2010, 118:370-374.

43. Zhang FF, Cardarelli R, Carroll J, Fulda KG, Kaur M, Gonzalez K, Vishwanatha JK, Santella RM, Morabia A: Significant differences in global genomic DNA methylation by gender and race/ethnicity in peripheral blood. Epigenetics 2011, 6:623-629.

44. El-Maarri O, Walier M, Behne F, van UJ, Singer H, Diaz-Lacava A, Nusgen N, Niemann B, Watzka M, Reinsberg J, van dV, Wienker T, Stoffel-Wagner B, Schwaab R, Oldenburg J: Methylation at global LINE-1 repeats in human blood are affected by gender but not by age or natural hormone cycles. PLoS One 2011, 6:e16252.

45. Singer $H$, Walier M, Nusgen $N$, Meesters $C$, Schreiner F, Woelfle J, Fimmers R, Wienker T, Kalscheuer VM, Becker T, Schwaab R, Oldenburg J, El-Maarri O: Methylation of $\mathrm{L} 1 \mathrm{Hs}$ promoters is lower on the inactive $\mathrm{X}$, has a 
tendency of being higher on autosomes in smaller genomes and shows inter-individual variability at some loci. Hum Mol Genet 2012, 21:219-235.

46. Poage GM, Houseman EA, Christensen BC, Butler RA, Avissar-Whiting M, McClean MD, Waterboer T, Pawlita M, Marsit CJ, Kelsey KT: Global hypomethylation identifies loci targeted for hypermethylation in head and neck cancer. Clin Cancer Res 2011, 17:3579-3589.

47. Weisenberger DJ, Campan M, Long TI, Kim M, Woods C, Fiala E, Ehrlich M, Laird PW: Analysis of repetitive element DNA methylation by MethyLight. Nucleic Acids Res 2005, 33:6823-6836.

48. Wu HC, Delgado-Cruzata L, Flom JD, Kappil M, Ferris JS, Liao Y, Santella RM, Terry MB: Global methylation profiles in DNA from different blood cell types. Epigenetics 2011, 6:76-85.

49. Kazazian HH Jr, Goodier JL: LINE drive. retrotransposition and genome instability. Cell 2002, 110:277-280.

50. Daskalos A, Nikolaidis G, Xinarianos G, Savvari P, Cassidy A, Zakopoulou R, Kotsinas A, Gorgoulis V, Field JK, Liloglou T: Hypomethylation of retrotransposable elements correlates with genomic instability in nonsmall cell lung cancer. Int J Cancer 2009, 124:81-87.

51. Lee DH: Persistent organic pollutants and obesity-related metabolic dysfunction: focusing on type 2 diabetes. Epidemiol Health 2012, 34:e2012002.

52. Ruzzin J, Petersen R, Meugnier E, Madsen L, Lock EJ, Lillefosse H, Ma T, Pesenti S, Sonne SB, Marstrand TT, Malde MK, Du ZY, Chavey C, Fajas L, Lundebye AK, Brand CL, Vidal H, Kristiansen K, Froyland L: Persistent organic pollutant exposure leads to insulin resistance syndrome. Environ Health Perspect 2010, 118:465-471.

53. Sell $H$, Eckel J: Adipose tissue inflammation: novel insight into the role of macrophages and lymphocytes. Curr Opin Clin Nutr Metab Care 2010, 13:366-370.

54. Winer DA, Winer S, Shen L, Wadia PP, Yantha J, Paltser G, Tsui H, Wu P, Davidson MG, Alonso MN, Leong HX, Glassford A, Caimol M, Kenkel JA, Tedder TF, McLaughlin T, Miklos DB, Dosch HM, Engleman EG: B cells promote insulin resistance through modulation of $\mathrm{T}$ cells and production of pathogenic $\lg G$ antibodies. Nat Med 2011, 17:610-617.

55. Ulrich CM, Reed MC, Nijhout HF: Modeling folate, one-carbon metabolism, and DNA methylation. Nutr Rev 2008, 66(Suppl 1):S27-S30.

doi:10.1186/1868-7083-4-10

Cite this article as: Turcot et al.: LINE-1 methylation in visceral adipose tissue of severely obese individuals is associated with metabolic syndrome status and related phenotypes. Clinical Epigenetics 2012 4:10.

\section{Submit your next manuscript to BioMed Central and take full advantage of:}

- Convenient online submission

- Thorough peer review

- No space constraints or color figure charges

- Immediate publication on acceptance

- Inclusion in PubMed, CAS, Scopus and Google Scholar

- Research which is freely available for redistribution 